\title{
Simpson's Method for Solution of Nonlinear Equation
}

\author{
Hamideh Eskandari \\ Department of Mathematics, Payame Noor University, Tehran, Iran \\ Email: h_eskandari@pnu.ac.ir
}

How to cite this paper: Eskandari, H. (2017) Simpson's Method for Solution of Nonlinear Equation. Applied Mathematics, 8, 929-933.

https://doi.org/10.4236/am.2017.87073

Received: June 5, 2017

Accepted: July 11, 2017

Published: July 14, 2017

Copyright (C) 2017 by author and Scientific Research Publishing Inc.

This work is licensed under the Creative

Commons Attribution International

License (CC BY 4.0).

http://creativecommons.org/licenses/by/4.0/

\begin{abstract}
The programs offered for solving nonlinear equations, usually the old method, such as alpha, chordal movement, Newton, etc. have been used. Among these methods may Newton's method of them all be better and higher integration. In this paper, we propose the integration method for finding the roots of nonlinear equation we use. In this way, Newton's method uses integration methods to obtain. In previous work, [1] and [2] presented numerical integration methods such as integration, trapezoidal and rectangular integration method that are used. The new method proposed here, uses Simpson's integration. With this method, the approximation error is reduced. The calculated results show that this hypothesis is confirmed.
\end{abstract}

\section{Keywords}

Convergence, Newton Method, Simpson Method, Nonlinear Equation, Iterative Method

\section{Introduction}

Let $f: R \rightarrow R$ be a smooth nonlinear function with a simple root $x^{*}$, i.e. $f\left(x^{*}\right)=0$ and $f^{\prime}\left(x^{*}\right) \neq 0$. We consider iterative methods for the calculation of $x^{*}$ that uses $f$ and $f^{\prime}$ but not the higher derivatives of $f$ and that generalizes the Newton method. Modifications for multiple roots will not be considered in the present contribution.

To find the roots of an equation of nonlinear methods, there are many methods. Most famous method to find the approximate root of $x^{*}$ from the equation, non-linear and using the first derivative, is what called Newton's method. ([3]-[8]).

We know that Newton's method, an iterative procedure is to obtain an approximate root of the equation $f(x)=0$, with an initial guess $x_{0} \in R$, for $n=0,1,2, \cdots$ values 


$$
x_{n+1}=x_{n}-\frac{f\left(x_{n}\right)}{f^{\prime}\left(x_{n}\right)}
$$

Calculates show that this formula is repeated, with the convergence of order two.

\section{Elementarily Methods}

Newton's iteration formula in different ways and in many ways can be found

[3]-[8]. But in this paper specific integration methods, we use. According to the definite integral

$$
\int_{x_{n}}^{x} f^{\prime}(t) \mathrm{d} t=f(x)-f\left(x_{n}\right)
$$

can write

$$
f(x)=f\left(x_{n}\right)+\int_{x_{n}}^{x} f^{\prime}(t) \mathrm{d} t
$$

The definite integral in this regard can be calculated by different methods. If this is the definite integral of the square method [1] to obtain, can be written

$$
\int_{x_{n}}^{x} f^{\prime}(t) \mathrm{d} t \cong\left(x-x_{n}\right) f^{\prime}\left(x_{n}\right)
$$

After placement in relation to certain integration, we get the following statement.

$$
f(x) \cong f\left(x_{n}\right)+\left(x-x_{n}\right) f^{\prime}\left(x_{n}\right)
$$

According to $f(x)=0$ is due to the new value $x=x_{n}-\frac{f\left(x_{n}\right)}{f^{\prime}\left(x_{n}\right)}$ to obtain the same formula is repeated Newton [9].

As well as to find solutions integrator can be used as [1] of midpoint method.

$$
\int_{x_{n}}^{x} f^{\prime}(t) \mathrm{d} t \cong\left(x-x_{n}\right) f^{\prime}\left(\frac{x_{n}+x}{2}\right)
$$

And with Placement $x=x_{n}-\frac{f\left(x_{n}\right)}{f^{\prime}\left(x_{n}\right)}$ that is Newton iteration, to new iteration will reach a formula.

$$
x_{n+1}=x_{n}-\frac{f\left(x_{n}\right)}{f^{\prime}\left(x_{n}-\frac{f\left(x_{n}\right)}{2 f^{\prime}\left(x_{n}\right)}\right)}
$$

However, if we use trapezoidal method and midpoint method instead of rectangular method [1] [2], then the method can be written

$$
\int_{x_{n}}^{x} f^{\prime}(t) \mathrm{d} t \cong \frac{\left(x-x_{n}\right)}{2}\left[f^{\prime}\left(x_{n}\right)+f^{\prime}(x)\right]
$$

And the placement of certain integration, we get the following statement.

$$
f(x) \cong f\left(x_{n}\right)+\frac{\left(x-x_{n}\right)}{2}\left[f^{\prime}\left(x_{n}\right)+f^{\prime}(x)\right]
$$

And according to $f(x)=0$ is the new value of $x=x_{n}-\frac{2 f\left(x_{n}\right)}{\left[f^{\prime}\left(x_{n}\right)+f^{\prime}(x)\right]}$ to 
obtain by replacing $f^{\prime}(x)$ with $f^{\prime}\left(x_{n+1}\right)$, where $x_{n+1}=x_{n}-\frac{f\left(x_{n}\right)}{f^{\prime}\left(x_{n}\right)}$ is Newton repeated the following three methods to obtain explicit order.

$$
x_{n+1}=x_{n}-\frac{2 f\left(x_{n}\right)}{f^{\prime}\left(x_{n}\right)+f^{\prime}\left(x_{n}-\frac{f\left(x_{n}\right)}{f^{\prime}\left(x_{n}\right)}\right)}
$$

This relationship, modified Newton iteration formula [10] is.

\section{Preliminary Results}

Now back to the original Equation (3) return.

To find the definite integral in the above equation, we use the method of Simpson [3]. We can write

$$
\int_{x_{n}}^{x} f^{\prime}(t) \mathrm{d} t=\frac{\frac{x-x_{n}}{2}}{3}\left(f^{\prime}(x)+4 f^{\prime}\left(\frac{x+x_{n}}{2}\right)+f^{\prime}\left(x_{n}\right)\right)
$$

By substituting the equation can be written

$$
f(x)=f\left(x_{n}\right)+\frac{x-x_{n}}{6}\left(f^{\prime}(x)+4 f^{\prime}\left(\frac{x+x_{n}}{2}\right)+f^{\prime}\left(x_{n}\right)\right)
$$

According to the $f(x)=0$, we will gain new value

$$
x=x_{n}-\frac{6 f\left(x_{n}\right)}{\left[f^{\prime}(x)+4 f^{\prime}\left(\frac{x+x_{n}}{2}\right)+f^{\prime}\left(x_{n}\right)\right]} \text { and substitution } x \text { with } x_{n+1} \text { expli- }
$$

cit method to obtain, where in $x_{n+1}=x_{n}-\frac{f\left(x_{n}\right)}{f^{\prime}\left(x_{n}\right)}$ is Newton method.

$$
x_{n+1}=x_{n}-\frac{6 f\left(x_{n}\right)}{\left[f^{\prime}\left(x_{n}-\frac{f\left(x_{n}\right)}{f^{\prime}\left(x_{n}\right)}\right)+4 f^{\prime}\left(\frac{x_{n}-\frac{f\left(x_{n}\right)}{f^{\prime}\left(x_{n}\right)}+x_{n}}{2}\right)+f^{\prime}\left(x_{n}\right)\right]}
$$

And then we'll simplify.

$$
x_{n+1}=x_{n}-\frac{6 f\left(x_{n}\right)}{\left[f^{\prime}\left(x_{n}-\frac{f\left(x_{n}\right)}{f^{\prime}\left(x_{n}\right)}\right)+4 f^{\prime}\left(x_{n}-\frac{f\left(x_{n}\right)}{2 f^{\prime}\left(x_{n}\right)}\right)+f^{\prime}\left(x_{n}\right)\right]}
$$

This relationship, a new iterative method is a convergence of order higher than two.

Methods that have already been presented, rectangular and trapezoidal integration method is used. These methods have convergence times lower than Simpson's method. In the future we will see that this method is superior to other methods and convergence is it better than before.

Here, all computing software Maple is done and we have one of the following stop conditions: 
Table 1. Example 1.

\begin{tabular}{ccc}
\hline$n$ & $x_{n}$ & $\left|f\left(x_{n}\right)\right|$ \\
\hline 1 & 1.6504206952163954715 & 0.34641095924425665672 \\
2 & 1.9305183053827568405 & 0.00547642190321585418 \\
3 & 1.9345632028456436684 & $1.071944817796 \times 10^{-8}$ \\
4 & 1.9345632107520242676 & 0. \\
5 & 1.9345632107520242676 & 0. \\
\hline
\end{tabular}

Table 2. Example 2.

\begin{tabular}{ccc}
\hline$n$ & $x_{n}$ & $\left|f\left(x_{n}\right)\right|$ \\
\hline 1 & 0.78027135582726141440 & 0.01676581394101499529 \\
2 & 0.77288330212111547221 & $7.7296437954397 \times 10^{-7}$ \\
3 & 0.77288295914921011288 & $7 \times 10^{-20}$ \\
4 & 0.77288295914921011285 & 0. \\
5 & 0.77288295914921011285 & 0. \\
\hline
\end{tabular}

(I) $\left|x_{n+1}-x_{n}\right|<\varepsilon$

(II) $\left|f\left(x_{n+1}\right)\right|<\varepsilon$

In each of them $\varepsilon=10^{-1000}$ and also all computations were done using Maple using 128 digit floating point arithmetic (Digits: $=128$ ).

\section{Numerical Experiments}

In this section, we will test several functions in obtained iteration formula.

Example 1:

Consider the equation $f(x)=\sin x-x+1=0$. Starting from the point $x_{0}=1.0$, we obtain the value of 1.9345632107520242676 , if 1.9345632107520242676 is the exact answer. Different iterations of this method in Table 1.

Example 2:

Consider the equation $f(x)=x^{3}-\mathrm{e}^{-x}=0$. Starting from the point $x_{0}=1.0$, we obtain the value of 0.77288295914921011285 , if

0.77288295914921011285 is the exact answer. Different iterations of this method in Table 2.

\section{Conclusion}

In this paper, to solve a nonlinear equation formula offered new iteration, we have seen that this formula iteration was obtained using Simpson integration. It was observed that using examples provided, its accuracy is higher than the accuracy of Newton iterative method.

\section{Acknowledgements}

This article is supported by Payame Noor University. 


\section{References}

[1] Frontini, M. and Sormani, E. (2003) Some Variant of Newton's Method with ThirdOrder Convergence. Applied Mathematics and Computation, 140, 419-426. https://doi.org/10.1016/S0096-3003(02)00238-2

[2] Homeier, H.H.H. (2005) On Newton-Type Methods with Cubic Convergence. Applied Mathematics and Computation, 176, 425-432. https://doi.org/10.1016/j.cam.2004.07.027

[3] Atkinson, K.E. (1988) An Introduction to Numerical Analysis. John Wiley \& Sons.

[4] Cheney, E.W. and Kincaid, D. (2003) Numerical Mathematics and Computing. Thomson Learning.

[5] Hildebrand, F.B. (1974) Introduction to Numerical Analysis. Tata McGraw-Hill.

[6] Quarteroni, A., Sacco, R. and Saleri, F. (2000) Numerical Mathematics. Springer.

[7] Stewart, G.W. (1996) After Notes on Numerical Analysis. SIAM.

[8] Stoer, J. and Bulirsch, R. (1983) Introduction to Numerical Analysis. Springer-Verlag.

[9] Weerakoom, S. and Fernando, T.G.I. (2000) A Variant of Newton_s Method with Accelerated Third-Order Convergence. Applied Mathematics Letters, 13, 87-93. https://doi.org/10.1016/S0893-9659(00)00100-2

[10] Kou, J.S., Li, Y.T. and Wang, X.H. (2006) On Modified Newton Methods with Cubic Convergence. Applied Mathematics and Computation, 176, 123-127. https://doi.org/10.1016/j.amc.2005.09.052

Submit or recommend next manuscript to SCIRP and we will provide best service for you:

Accepting pre-submission inquiries through Email, Facebook, LinkedIn, Twitter, etc. A wide selection of journals (inclusive of 9 subjects, more than 200 journals) Providing 24-hour high-quality service User-friendly online submission system Fair and swift peer-review system Efficient typesetting and proofreading procedure Display of the result of downloads and visits, as well as the number of cited articles Maximum dissemination of your research work

Submit your manuscript at: http://papersubmission.scirp.org/

Or contact am@scirp.org 